\title{
Clinical events relating to intraventricular haemorrhage in the newborn
}

\author{
M. FUJIMURA, D. M. SALISBURY, R. O. ROBINSON, P. HOWAT, P. M. EMERSON, \\ J. W. KEELING, AND J. P. M. TIZARD
}

Department of Paediatrics, John Radcliffe Hospital, and Department of Pathology, Radcliffe Infirmary, Oxford

SUMMARY Continuous measurements of arterial pressures, heart rates, respiratory movements, and respiratory rates were made from birth in 44 infants at risk from intraventricular haemorrhage (IVH). 17 babies died with IVH, in 10 of whom the event was timed objectively. Events in these babies were compared with survivors of similar birthweights, gestational ages, severity of birth asphyxia, and severity of hyaline membrane disease (HMD). IVH followed severe HMD and was associated with cessation of the babies' own respiratory efforts while on a ventilator and also with characteristic cardiorespiratory events. The minimum arterial pressure before IVH was lower than in comparable babies who survived. It is suggested that fluctuations of systemic blood pressure from initial low levels may be important in the pathogenesis of IVH. It is possible that changes in cerebral blood flow are of even greater significance.

Intraventricular haemorrhage (IVH) is a major cause of death in low birthweight infants. The succession of new ideas about its aetiology testifies to our continuing ignorance. These ideas have included cerebral congestion at birth (Schwartz, 1927), structural vulnerability of the immature germinal matrix (Ruchensteiner and Zollner, 1929; Hemsath, 1934), maternal toxaemia (Craig, 1938), hypoxic venous congestion and capillary damage (Gruenwald, 1951), venous stasis and infarction (Larroche, 1964; Ross and Dimette, 1965; Towbin, 1968; Leech and Kohman, 1974), coagulation disorders (Gray et al., 1968; Schenck et al., 1968; Cade et al., 1969; Thomas and Burnard, 1973), acute severe hypoxia followed by a latent interval (Harrison et al., 1968), jugular compression (Vert et al., 1973), venous hypertension secondary to hypoxic cardiac failure (Cole et al., 1974), hypertonic alkali solutions (Simmons et al., 1974; Wigglesworth et al., 1975),

John Radcliffe Hospital, Oxford,

Department of Paediatrics

J. P. M. TIZARD, professor of paediatrics

M. FUJIMURA, research fellow in paediatrics

D. M. SALISBURY, research fellow in paediatrics

R. O. ROBINSON, lecturer in paediatrics

P. HOWAT, research sister

Department of Pathology

P. M. EMERSON, consultant haematologist

J. W. KEELING, consultant pathologist and changes in cerebral blood flow (Wigglesworth and Pape, 1978). While theories about events before or at birth are difficult to test, theories concerning events in postnatal life can be investigated. However it is essential to distinguish events preceding IVH -and possibly contributory to it-from those occurring during and after and possibly caused by IVH. We made continuous observations for up to 3 days after birth on infants of $<33$ weeks' gestation or $<1500 \mathrm{~g}$ birthweight. In this paper the clinical events of those infants who died with IVH are described and related with events to the presumed time of the haemorrhage.

\section{Patients and methods}

44 infants $<1500 \mathrm{~g}$ birthweights or $<33$ weeks' gestation were studied during a 15-month period from November 1974 (Fig. 1). 17 of these babies survived and serve as controls as none of them gave evidence of acute IVH in the neonatal period or has subsequently developed sequelae-such as hydrocephalus. Necropsy was performed on all 27 babies who died; 17 died with IVH. The babies dying without IVH were not used as controls as 3 died between 6 and 8 months after birth as a result of complications experienced in the perinatal period (and are not therefore comparable with neonatal 
Table 1 Details of babies dying with IVH and survivors

\begin{tabular}{lcc}
\hline & $\begin{array}{l}\text { Babies dying } \\
\text { with IVH }(n=17)\end{array}$ & $\begin{array}{l}\text { Survivors } \\
(n=17)\end{array}$ \\
\hline $\begin{array}{l}\text { Gestational age (weeks) } \\
\text { Birthweight (g) }\end{array}$ & $\begin{array}{cc}27 \cdot 9(26-32) \\
\text { Male : female }\end{array}$ & $\begin{array}{c}30 \cdot 4(27-33) \\
1035(650-1420)\end{array}$ \\
\hline
\end{tabular}

Figures in parentheses indicate the range.

deaths or survivors), and in only 3 of the remaining babies were arterial pressure measurements available. Details of the babies surviving and the babies dying with IVH are given in Table 1.36 of the 44 (total study) babies had hyaline membrane disease (HMD) and 31 of these were ventilated. 16 of the 17 babies dying with IVH were ventilated because of severe HMD; IVH occurred in a baby with tracheooesophageal fistula after gastrostomy was performed. During the 15-month period of the study a further 47 babies of $<1500 \mathrm{~g}$ birthweights or $<33$ weeks' gestation were admitted to our unit. These were not studied either because monitoring facilities were in use elsewhere, or because attempts to pass umbilical arterial catheters were unsuccessful, or because an umbilical arterial catheter passed at birth was removed only a few hours later as the clinical condition of the infant was good. Only 9 of these 47 babies died, 3 with IVH. The study group therefore did not represent the consecutive admissions in this birthweight gestational age group, and included a greater proportion of the most severely ill babies. Umbilical arterial catheters were introduced into 40 infants, generally at birth and certainly within 6 hours after birth. The catheter was passed to the level of L4 and the position confirmed by $x$-ray. Continuous arterial pressure measurements were made in 40 infants (Elcomatic pressure transducers) and recorded using a Devices M19 recorder. Mean hourly arterial pressures were derived manually by abstracting systolic and diastolic pressures from the records at 5-min intervals. The heart rate was derived either from the arterial pressure or from the ECG trace. Respiratory movements were recorded by a magnetometer (Rolfe, 1975) or by an impedance pneumograph (Air Shields Ltd), and from these, the respiratory rate was derived. A thermistor was inserted to $6 \mathrm{~cm}$ rectally and continuous core temperature was recorded (Electrolaboratoriet temperature recorder). In 12 infants an intravascular oxygen electrode (G. D. Searle Ltd) gave a continuous record of $\mathrm{PaO}_{2}$. In all the infants blood-gas and $\mathrm{pH}$ measurements were made 4-hourly or at shorter intervals by the resident staff. Haematocrit was also measured 4-hourly on samples taken into dry syringes and measured in triplicate. Haemolysed samples were discarded. The infants were continuously observed by one of us in turn until death or recovery. Whenever a change occurred in the continuous records, any change in the infant's behaviour or environment was noted and vice versa. The occipito-frontal circumference was measured at least daily and up to 6-hourly in some infants with disposable paper tape measures.

IVH was timed by two methods described in detail elsewhere (Emerson et al., 1977). Both methods depend on the effects of serial small blood transfusions given to improve tissue perfusion and oxygenation and to replace blood withdrawn for sampling. Comparison of the changes in proportions of transfused cells found in the intraventricular clot at necropsy restricted the timing of IVH to the period between two consecutive blood transfusions-'the IVH period'. By noting the rise in the proportion of transfused cells produced by infusion of a known red cell mass, changes in the baby's original red cell mass could be followed during life. A fall in fetal red cell mass occurred either before or during the period indicated by clot analysis. In this paper, 'before IVH' or 'during and after IVH' relate to the earliest time IVH could have occurred from the timing technique.

\section{Results}

Before IVH. Roberton and Tizard (1975) showed that establishment of adequate ventilation after resuscitation at birth is a powerful predictor for subsequent survival from HMD. Thus in analysing our results babies dying with IVH were divided into two groups (Fig. 1). Group $1(n=9)$ were not able to support adequate ventilation from 15 minutes after birth. Group $2(n=8)$ established spontaneous ventilation after resuscitation. Six of the 17 survivors were of comparable birthweights and gest-

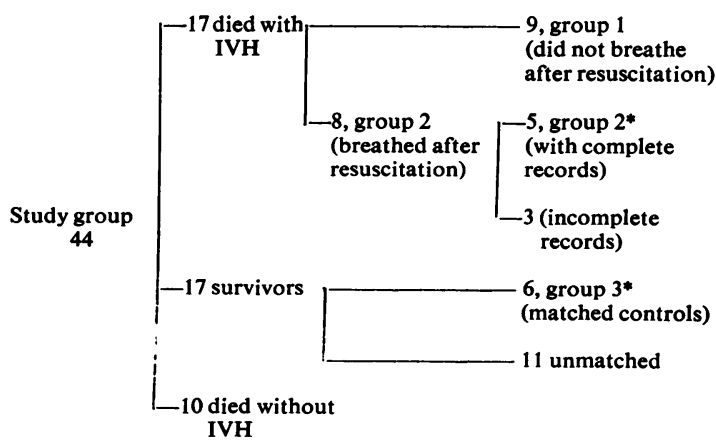

Fig. 1 Division of the study group in order to identify comparable subgroups of babies (marked with an asterisk) who are likely to differ only with respect to factors specific for IVH (see text). 
Table 2 Details of babies dying with IVH who breathed after initial resuscitation (group 2), and survivors matched for gestational ages (group 3)

\begin{tabular}{lcc}
\hline & $\begin{array}{l}\text { Babies dying } \\
\text { with IVH }(n=5)\end{array}$ & $\begin{array}{l}\text { Survivors } \\
(n=6)\end{array}$ \\
\hline Gestational age (weeks) & $29 \cdot 1(28-32)$ & $\begin{array}{r}29 \cdot 2(27-32) \\
\text { Birthweight (g) }\end{array}$ \\
Male : female & $1153(945-1420)$ & $1152(630-1860)$ \\
\hline
\end{tabular}

Figures in parentheses indicate the range.

ations as group 2 and were ventilated for severe HMD; they are identified as group 3 (Table 2). The 9 babies in group 1 had gestational ages of 28 weeks or less and all but 2 were born by the breech. Their mothers went into labour spontaneously and preterm labour had not been anticipated. The 8 babies in group 2 and the 6 in group 3 had gestational ages of at least 28 weeks. All but one of group 2 were delivered by caesarean section for maternal indications; in group 3 there were 2 caesarean sections, one breech delivery, and 3 vertex deliveries.

In respect of the degree of birth asphyxia in each group, cord blood-gas and $\mathrm{pH}$ data (obtained immediately after birth from clamped sections of cord) were not sufficient to allow comparisons. Clinically, it is evident that the babies in group 1, none of whom maintained spontaneous respiration, were more severely asphyxiated at birth than those in groups 2 and 3 who initially maintained respiration after resuscitation. A comparison of groups 2 and 3 shows that at birth there were more severely asphyxiated babies in the latter-that is the survivors-but numbers are too small for statistical analysis. The core temperatures up to 6 hours after birth are shown in Table 3 for babies in groups 1 , 2 , and 3. The babies in group 1 had core temperatures lower at 2, 3, 5, and 6 hours after birth $(\mathrm{P}<0.05)$ than the remaining babies dying with IVH or survivors. Babies in groups 2 and 3 maintained similar core temperatures.

For all these reasons we considered that the babies in group 1 were different from those in groups 2 and 3 but that these last two groups are suitable for comparison. By choosing survivors of similar birthweights and gestational ages, all of

Table 3 Mean core temperatures at times after birth in groups 1,2 , and $3\left({ }^{\circ} C \pm S D\right)$

\begin{tabular}{llll}
\hline Hours & Group 1 & Group 2 & Group 3 \\
\hline 1 & $34 \cdot 2 \pm 2 \cdot 0$ & $35 \cdot 8 \pm 0 \cdot 8$ & $36 \cdot 6 \pm 0 \cdot 2$ \\
2 & $33 \cdot 8 \pm 2 \cdot 0^{*}$ & $36 \cdot 0 \pm 0 \cdot 9$ & $36 \cdot 1 \pm 0 \cdot 2$ \\
3 & $34 \cdot 4 \pm 1 \cdot 0^{*}$ & $36 \cdot 5 \pm 1 \cdot 0$ & $36 \cdot 4 \pm 0 \cdot 2$ \\
4 & $34 \cdot 4 \pm 1 \cdot 7^{*}$ & $36 \cdot 6 \pm 0 \cdot 9$ & $36 \cdot 2 \pm 0 \cdot 2$ \\
5 & $34 \cdot 6 \pm 1 \cdot 6^{*}$ & $36 \cdot 7 \pm 0 \cdot 7$ & $36 \cdot 6 \pm 0 \cdot 2$ \\
6 & $34 \cdot 8 \pm 1 \cdot 8^{*}$ & $36 \cdot 8 \pm 0.9$ & $36 \cdot 9 \pm 0 \cdot 1$ \\
\hline
\end{tabular}

*P<0.05 (group 1 compared with group 2 ). whom were ventilated for severe HMD, we obtained two groups who were likely to differ only in respect to factors specific for IVH. In fact they were not comparable in respect of birth asphyxia (assessed clinically) in that the survivors (group 3) were in a poorer condition at birth than those in group 2 . However all these babies (group 3) established spontaneous respiration within 15 minutes of delivery, and this appears to give a better prediction of survival than does the degree of asphyxia judged clinically. After excluding babies in whom attempts at umbilical arterial catheterisation or at timing of IVH were unsuccessful, 5 babies from group 2 were available for comparison with 6 survivors from group 3 (Table 2). Fig. 2 shows the mean hourly arterial pressures in groups 2 and 3, abstracted from the continuous records. The increase in mean arterial pressure by 6 hours after birth (estimated as a percentage change from the mean arterial pressure 2 hours after birth) was significantly greater in babies in group 2 than in group 3. Although the mean arterial pressures of the two groups were not significantly different from each other at any time after birth, this difference in relative change during the first 6 hours after birth appeared to be due to a rise in the mean arterial pressure from the low levels in babies in group 2, whereas in survivors the arterial pressure either remained stable or fell slightly. In 3 babies in group 2 there was an additional acute episode of hypotension after the first 6 hours after birth and preceding IVH. The mean of the lowest systolic arterial pressure in all 5 babies before IVH $(26 \cdot 8 \pm 7 \cdot 05 \mathrm{SD} \mathrm{mmHg})$ was lower than the mean of the lowest systolic arterial pressure observed at any time in the 6 survivors $(37 \cdot 8 \pm 5 \cdot 9 \mathrm{SD} \mathrm{mmHg})$. The mean of the highest blood pressure in group 2

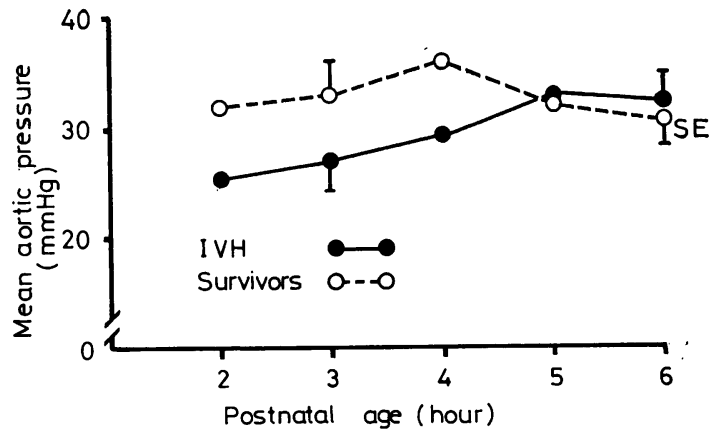

Fig. 2 Changes in arterial pressures in babies who subsequently died with IVH and those who survived of similar gestational ages. Degree of change from the 1st to 6th hour, expressed as a percentage of the initial value, is significantly different between the two groups $(P<0 \cdot 05)$. 
Table 4 The mean $\pm S D$ of the lowest $\mathrm{PaO}_{2}$, highest $\mathrm{PaCO}_{2}$, and lowest $\mathrm{pH}$ in groups 2 and $3(\mathrm{mmHg})$

\begin{tabular}{|c|c|c|c|}
\hline Group & Lowest $\mathrm{PaO}_{2}$ & Highest $\mathrm{PaCO}_{2}$ & Lowest pH \\
\hline $2(n=5)$ & $\begin{array}{l}32 \\
\pm 5.7 \mathrm{SD}\end{array}$ & $\begin{array}{l}64 \\
\pm 35 \cdot 0 \mathrm{SD}\end{array}$ & $\begin{array}{l}7.05 \\
\pm 0.12 \mathrm{SD}\end{array}$ \\
\hline $3(n=6)$ & $\begin{array}{l}38 \\
\pm 11.9 \mathrm{SD}\end{array}$ & $\begin{array}{l}71 \\
\pm 17 \cdot 8 \mathrm{SD}\end{array}$ & $\begin{array}{l}7.07 \\
\pm 0.09 \mathrm{SD}\end{array}$ \\
\hline
\end{tabular}

Group 2 before IVH period; group 3 first 72 hours.
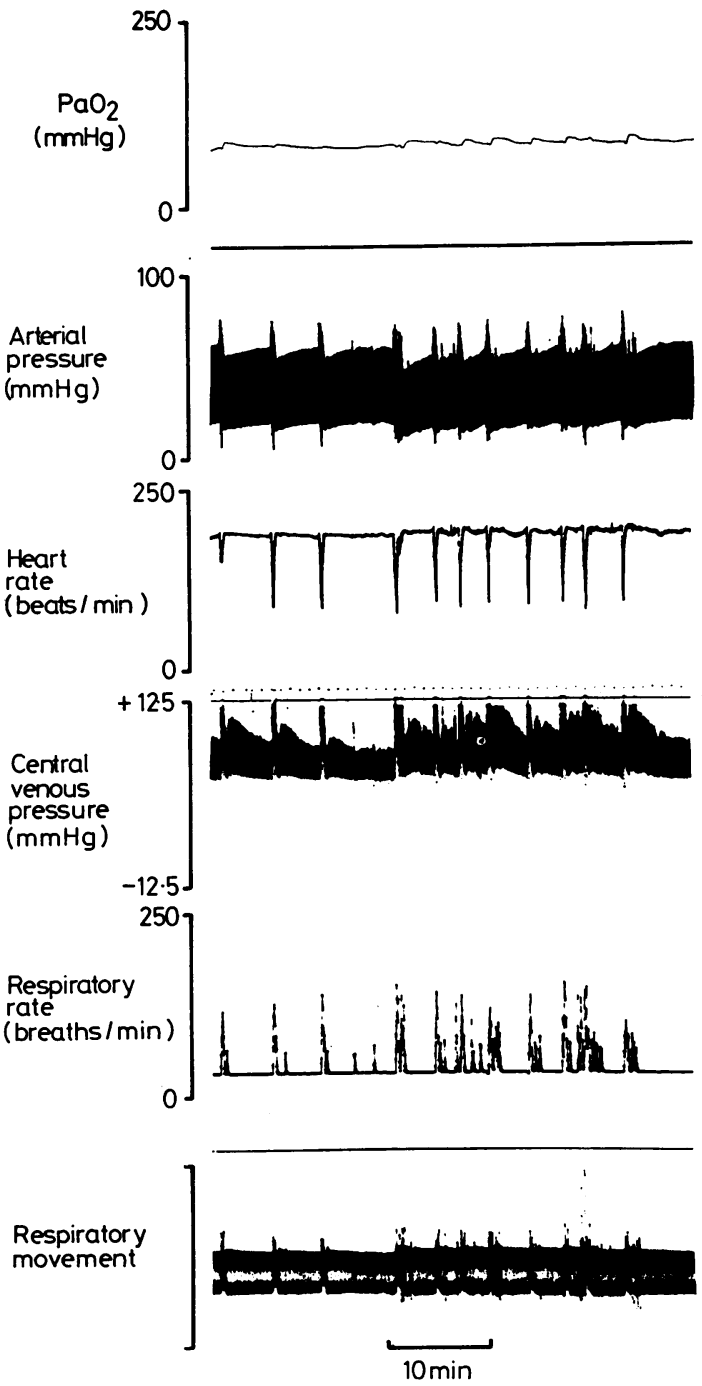

Fig. 3 Six-channel record displaying discrete cardiorespiratory events seen only in IVH babies. The lower two traces indicate the episodic gasping movements which are accompanied by a simultaneous increase in the arterial and central venous pressures and reflex bradycardia. 11 such events appear on the record. was $59 / 34 \pm 13 / 10 \mathrm{SD} \mathrm{mmHg}$ while it was $58 / 38 \pm$ $5 / 6 \mathrm{SD} \mathrm{mmHg}$ in group 3.

Although all the babies in groups 2 and 3 were being mechanically ventilated and therefore attempts were being made to keep the blood-gases within acceptable limits, extremes of hypoxia and hypercapnia did occur. These extremes are shown in Table 4. The differences are not significant.

During and after IVH. In the likely consequences of IVH, babies in groups 1 and 2 did not differ from each other. The proportion of babies who had a significant fall in haematocrit, fits, or rise in anterior fontanelle tension was similar in each group. They are therefore considered together for comparison with babies surviving. Eight of the 17 babies dying with IVH had fits. In most these were tonic but occasionally a baby had a multi-focal clonic fit. Tonic fits were accompanied by pronounced cardiorespiratory events. An abrupt increase in arterial pressure accompanied by a falling heart rate was associated with a few deep inspiratory gasps, as shown in Fig. 3. In 3 babies similar cardiorespiratory events were not accompanied by visible fits. They were clearly distinguishable from fluctuations which occurred during severe acidosis in a few babies and which we interpreted as Traube-Hering waves. These cardiorespiratory events were not seen in any of the surviving babies. Examination of the respiratory wave form distinguished the babies' own respiratory efforts from movements induced by the ventilator. In 7 babies, respiratory efforts ceased during and after the IVH period. In 5 of the 17 babies (groups 1 and 2) there were dramatic cardiorespiratory events or failure of spontaneous respiratory efforts before there was any other sign of IVH. In 6 babies of the 12 in whom serial measurements of the occipitofrontal circumference were available, there was a mean increase in occipito-frontal circumference of $0.88 \mathrm{~cm}$ (range 0.3-1.5) after the IVH period. A mean fall in haematocrit of 0.125 (range $0.04-0.23$ ) took place in the 12 babies in whom serial haematocrit measurements were available. A rise in anterior

Table 5 Amounts of sodium bicarbonate (mmol) and THAM $(\mathrm{ml})$ infused before, and during and after the IVH period

\begin{tabular}{llll}
\hline & $\begin{array}{l}\text { Group 2 } \\
(n=5)\end{array}$ & & $\begin{array}{l}\text { Group 3 } \\
(n=6)\end{array}$ \\
\cline { 2 - 3 } & $\begin{array}{l}\text { Before } \\
\text { IVH }\end{array}$ & $\begin{array}{l}\text { During and } \\
\text { after IVH }\end{array}$ & $\begin{array}{l}\text { Total in first } \\
72 \text { hours }\end{array}$ \\
\hline $\begin{array}{l}\text { Sodium bicarbonate } \\
\text { (mmol) } \\
\text { Mean }\end{array}$ & 2.1 & 5.6 & 6.7 \\
$\begin{array}{l}\text { THAM (ml) } \\
\text { Mean }\end{array}$ & 2.0 & 17.8 & \\
\hline
\end{tabular}


fontanelle tension as detected by palpation was noted in 8 babies. A sudden fall in $\mathrm{pH}$ to a value of $<7 \cdot 1$ occurred in 8 babies Table 5 shows the alkali infused into babies of groups 2 and 3. It can be seen that the amounts of bicarbonate solution and tromethamine (THAM) were no different before the IVH period in group 2 from the totals given to group 3 but were much greater (THAM) during or after the IVH period The mean hourly infusion of base (1 mmol of sodium bicarbonate equivalent to $1 \mathrm{ml}$ $6 \%$ THAM) before the IVH period in group 2 was $0.09 \mathrm{ml} / \mathrm{kg}$ per hour. In group 3 this was 0.08 $\mathrm{ml} / \mathrm{kg}$ per hour for the first 72 hours

\section{Discussion}

The ability of an infant to breathe adequately within 15 minutes of birth was used to separate infants who subsequently had IVH into two groups; these groups differed from each other in other ways. The infants who were not able to support adequate ventilation within 15 minutes of birth (group 1) were of gestational ages 28 weeks or less and were acidotic at birth, usually considerably so. With the exception of one baby, all were born by the breech; this may reflect their prematurity and it has implications for the fate of premature infants who are to be born by the breech.

Babies in group 1 had significantly lower core temperatures in the first 6 hours after birth. Hypoxia and acidosis inhibit thermogenesis by brown fat (Oliver and Karlberg, 1963; Scopes and Ahmed, 1966). While we cannot be sure that the asphyxiated babies were not subjected to more cold stress during resuscitation after birth than the rest-particularly during umbilical catheterisation at birth-it is possible that the lower core temperature is due in part to inhibition of nonshivering thermogenesis. In the babies of group 1, the onset of IVH ranged from $<2$ to 21 hours after birth, estimated by the proportion of transfused cells in the IVH. IVH occurred despite rapid correction of hypothermia, hypotension, and acidosis. We suggest that the causes of IVH in this group operate before and during birth.

By contrast babies in group 2 who were of gestational ages of at least 28 weeks were nearly all delivered by elective caesarean section for maternal indications. They were not as asphyxiated at birth and all but one developed severe HMD. The onsets of the IVH periods in this group ranged from 12 to 72 hours after birth and were later than the onsets in group 1 . In babies of group 2 it is reasonable to look for the causes of IVH after birth. Comparison with babies in group 3 which should identify factors specific for IVH has allowed us to test current hypotheses concerning the aetiology of this con- dition. It has been suggested, for example, that IVH may be precipitated by alkali administration (Simmons et al., 1974; Wigglesworth, et al. 1975). The technique of timing the earliest occurrence of IVH allows comparisons to be made of the alkali administration before IVH rather than the administration needed as a consequence of IVH. The babies of group 2 who subsequently developed IVH were given no more alkali before the IVH period than surviving babies; some of them received no alkali before the IVH period.

Although babies in group 1 had core temperatures significantly lower than babies in group 2 , babies in group 2 had similar core temperatures as survivors. Hypothermia therefore is unlikely to predispose to IVH. Similarly the greatest arterial pressure observed in babies subsequently dying with IVH was identical with that of babies surviving, and the extremes of blood-gases were no different in the two groups either, suggesting that hypoxia, hypercarbia, and acidosis were not specific factors in the aetiology of IVH. It would appear that IVH can occur in the presence of normal arterial pressure.

The pronounced cardiorespiratory events which took place at the time of IVH were associated with tonic movements and were thought to be a consequence of seizure activity. The importance of timing of IVH is seen in evaluating these events. As in 2 babies the cardiorespiratory events occurred before and in 3 babies they occurred during the IVH period, it is tempting to ascribe to them an aetiological role. However, in 3 babies they took place after the fall in fetal red cell mass and it is probable therefore that they occurred as a consequence rather than as a cause of IVH. The only distinguishing feature that emerged from our comparison of events before the IVH period in babies in group 2 with events in babies in group 3 was that of hypotension. Although there is no evidence to support the suggestion that this is a causative relationship, we suggest that any hypothesis for the cause of IVH should take this finding into account. It is suggested that resulting from severe birth asphyxia, IVH babies may be subjected to cerebral ischaemic hypoxia, and then on restoration of normal arterial pressure there are areas of 'luxury perfusion' in the subependymal layer sufficient to initiate subependymal haemorrhage. This then ruptures into the lateral ventricles. It is possible that cerebral blood flow is of more critical importance than systemic blood pressure, but the relationship between these two variables in the newborn has yet to be determined (Cooke et al., 1977).

Turning to the events that took place during and after IVH, failure on the part of the baby to continue making spontaneous respiratory movements, 
while on the ventilator, was an equally reliable sign of IVH and accords with general clinical experience. A fall in haematocrit was a consistent finding during and after IVH and occurred either alone or in combination either with a rise in anterior fontanelle tension or with fits in 15 of the 17 babies dying with IVH. In addition, a fall in fetal red cell mass took place at the same time as the onset of other signs of IVH and was not observed in any surviving baby. Where a blood transfusion is given after the onset of IVH the diagnosis can be made during life, and is nearly always supported by close observations of clinical events.

The patients were under the care of Drs J. D. Baum, B. N. Bower, H. Ellis, M. Moncrieff, and D. Pickering, We should like to thank Dr P. Rolfe and Mr P. Sutton for their bioengineering assistance and Miss $P$. Townshend and her nursing colleagues for their help. P.H. was in receipt of a grant from the Medical Research Council(GE974-185c), and D.M.S. from the Sir William Coxen Trust Fund; M.F. was a British Council scholar.

\section{References}

Cade, J. F., Hairsh, J. I., and Martin, M. (1969). Placental barrier to coagulation factors: its relevance to the coagulation defect at birth and to haemorrhage in the newborn. British Medical Journal, 2, 281-283.

Cole, V. A., Durbin, G. M., Olaffson, A., Reynolds, E. O. R., Rivers, R. P. A., and Smith, J. F. (1974). Pathogenesis of intraventricular haemorrhage in newborn infants. Archives of Disease in Childhood, 49, 722-728.

Cooke, R. W. I., Rolfe, P., and Howat, P. (1977). A technique for the non-invasive estimation of cerebral blood flow in the newborn infant. Biomedical Engineering, 1, 263-266.

Craig, W.S. (1938). Intracranial haemorrhage in the newborn. A study of diagnosis and differential diagnosis based upon pathological and clinical findings in 126 cases. Archives of Disease in Childhood, 13, 89-134.

Emerson, P., Fujimura, M., Howat, P., Howes, D., Keeling, J. W., Robinson, R. O., Salisbury, D. M., and Tizard, J. P. M. (1977). Methods of timing intraventricular haemorrhage. Archives of Disease in Childhood, 52, 183-187.

Gray, O. P., Ackerman, A., and Fraser, A. J. (1968). Intracranial haemorrhage and clotting defects in low birthweight infants. Lancet, 1, 545-548.

Gruenwald, P. (1951). Subependymal cerebral hemorrhage in premature infants, and its relation to various injurious influences at birth. American Journal of Obstetrics and Gynecology, 61, 1285-1292.

Harrison, V. C., Heese, H. de V., and Kein, M. (1968). Intracranial haemorrhage associated with hyaline membrane disease. Archives of Disease in Childhood, 43, 116-120.
Hemsath, F. A. (1934). Ventricular cerebral hemorrhage in the newborn infant. A pathologic and etiologic study of twenty cases. American Journal of Obstetrics and Gynecology, 28, 343-354.

Larroche, J-C. (1964). Hémorragies cérébrales intraventriculaires chez la prématuré. I. Anatomie et pathophysiologie. Biologia neonatorum, 7, 26-56.

Leech, R. W., and Kohman, P. (1974). Subependymal and intraventricular hemorrhages in the newborn. American Journal of Pathology, 77, 465-476.

Oliver, T. K., Jr, and Karlberg, P. (1963). Gaseous metabolism in newly born human infants. American Journal of Diseases of Children, 105, 427-435.

Roberton, N. R. C., and Tizard, J. P. M. (1975). Prognosis for infants with idiopathic respiratory distress syndrome. British Medical Journal, 3, 271-274.

Rolfe, P. (1975). Development and evaluation of the displacement magnetometer for monitoring breathing in ill newborn infants. In Proceedings of the International Conference on Biomedical Transducers, Paris, November 1975. BIOCAPT, volume 2, B8.5, p. 453.

Ross, J. J., and Dimette, R. M. (1965). Subependymal cerebral hemorrhage in infancy. American Journal of Diseases of Children, 110, 531-542.

Ruchensteiner, E., and Zollner, F. (1929). Über die Blutungen im Gebiete der Vena terminalis bei Neugeborenen. Frankfurter Zeitschrift fur Pathologie, 37, 568-578.

Schenck, W., Karitzky, D., Pringsheim, W., and Künzer, W. (1968). Letter: Intravascular coagulation and hyaline membrane disease. Lancet, $2,1082$.

Schwartz, P. (1927). Im Die Traumatischen Schadigungen des Zentralnervensystems durch die Geburt. Anatomische Untersuckungen. Ergebnisse der inneren Medizin und Kinderheilkunde, 31, 165.

Scopes, J. W., and Ahmed, I. (1966). Indirect assessment of oxygen requirements in newborn babies by monitoring deep body temperature. Archives of Disease in Childhood, 41, 25-33.

Simmons, M. A., Adcock, E. W., III, Bard, H., and Battaglia, F. C. (1974). Hypernatremia and intracranial hemorrhage in neonates. New England Journal of Medicine, 291, 6-10.

Thomas, D. B., and Burnard, E. D. (1973). Prevention of intraventricular haemorrhage in babies receiving artificial ventilation. Medical Journal of Australia, 1, 933-936.

Towbin, A. (1968). Cerebral intraventricular hemorrhage and subependymal matrix infarction in the fetus of the premature newborn. American Journal of Pathology, 52, 121-139.

Vert, P., Andre, M., and Sibout, M. (1973). Letter: Continuous positive airways pressure and hydrocephalus. Lancet, 2, 319.

Wigglesworth, J. S., Keith, I. H., Girling, D. J., and Slade, S. (1975). Relation between intraventricular haemorrhage and membrane disease in the newborn infant (abstract). Archives of Disease in Childhood, 50, 825.

Wigglesworth, J. S., and Pape, K. E. (1978). An integrated model for haemorrhage and ischaemic lesions in the newborn brain. Early Human Development, 2, 179.

Correspondence to Professor J. P. M. Tizard, Department of Paediatrics, John Radcliffe Hospital. Headington, Oxford OX3 9DU.

Received 8 August 1978 